\title{
Publicidade, imaginário e consumo: anúncios no cotidiano feminino ${ }^{1}$
}

\section{Elisa Reinhardt Piedras}

\section{Resumo}

Nesta pesquisa, partimos do seguinte

problema: Como o imaginário e o consumo

atravessam a relação cotidiana das pessoas

com a publicidade? Como elas definem a sua

relação com a publicidade, que usos fazem

dela, que competências desenvolveram para

compreendê-la, como se apropriam do fluxo

publicitário? Logo, exploramos como o imaginário

atravessa a publicidade, a relação desta com 0

consumo na sua configuração pós-moderna; e

a comunicação persuasiva como tecnologia do

imaginário e da sedução, seu fundo, forma e

práticas do cotidiano. Através de uma estratégia

metodológica que mescla entrevistas e grupos

de discussão, observamos os relatos de mulheres

adultas sobre seu imaginário, suas práticas de

consumo e especialmente sua relação com a

publicidade; chegando a resultados que explicitam

condicionantes ligados à renda e a escolaridade.

\section{Palavras-chave}

Publicidade. Imaginário. Consumo.

Cotidiano. Mulher.

\section{Elisa Reinhardt Piedras | elisapiedras@hotmail.com}

Doutora em Comunicação pela Pontifícia Universidade Católica do Rio Grande do Sul - PUCRS. Professora da área de Publicidade e pesquisadora no Departamento de Comunicação da Universidade Federal do Rio Grande do Sul - UFRGS.

\section{Tema e estratégia teórico-metodológica}

Onipresente e (in)eficiente, talvez desviada para 0 (ir)real, (in)útil, a publicidade concentra possibilidades mas escapa às certezas. Sendo uma forma de comunicação persuasiva fortemente ligada ao mercado e à lógica capitalista, é freqüentemente abordada em termos de manipulação ou de outros olhares restritos, que desconsideram as sutilezas de sua presença no cotidiano, atravessada pelo imaginário, às vezes interseccionada com o consumo.

No campo da pesquisa em comunicação brasileira, a temática da publicidade ainda é incipiente. Em estudos anteriores (PIEDRAS, 2005), tentamos construir um mapa das relações da publicidade com seu contexto econômico, político e cultural. Logo revelaram-se suas ambigüidades, bem como as particularidades contraditórias do seu processo comunicativo, envolvendo as práticas de publicitários e consumidores. Através da metáfora do fluxo, exploramos os anúncios publicitários ofertados pela produção e apropriados pela recepção. 
Agora, é a intersecção operada pela publicidade entre 0 material e 0 simbólico, 0 consumo e 0 imaginário, que instiga nosso olhar.

Nesse cenário, nossa questão de pesquisa é: Como o imaginário e o consumo atravessam a relação cotidiana das pessoas com a publicidade? Como as pessoas definem a sua relação com a publicidade, que usos fazem dela, que competências desenvolveram para compreendêla, como se apropriam do fluxo publicitário?

Como objetivo, considerando a intersecção publicidade-imaginário-consumo, queremos explorar os relatos das pessoas sobre suas práticas e idéias relativas a isso no cotidiano, além de observar a apropriação que fazem do fluxo publicitário.

Especificamente, interessa-nos complexificar a abordagem da publicidade na pluralidade do cotidiano, indo além dos determinismos e das avaliações unidimensionais; explorar teoricamente como o imaginário atravessa a publicidade, a relação desta com o consumo na sua configuração pós-moderna, e a comunicação persuasiva como tecnologia do imaginário e da sedução, seu fundo, forma e práticas do cotidiano. Desta perspectiva, observamos os relatos de mulheres adultas sobre aspectos do seu imaginário e suas práticas de consumo, bem como da sua relação cotidiana com a publicidade, seus usos e competências de leitura, a apropriação que fazem de fluxo de anúncios; e exploramos essas relações em termos de generalidades femininas e distinções motivadas por variações de escolaridade, renda e idade.

Para compreender isso, reunimos nossos pressupostos epistemológicos: a sociologia compreensiva, trabalhada por Maffesoli (1988) desde $O$ conhecimento comum, destacando a necessidade de se pensar o social além do que é simplesmente utilitário, e agora tende a integrar todas as dimensões estéticas (oníricas, lúdicas e simbólicas), das quais se podem ver os efeitos, em cada momento da vida cotidiana; e a análise de recepção, através das idéias de MartínBarbero (2003), especialmente em Dos meios às mediações, propondo o deslocamento da produção à recepção e à complexidade do cotidiano, buscando re-ver o processo da comunicação.

Essa triangulação avança para 0 âmbito metodológico através da "combinação de metodologias diversas no estudo do mesmo fenômeno" (GOLDENBERG, 2003, p.63). Apesar da opção de trabalhar somente com técnicas de coleta e análise de dados qualitativas, integramos dados quantitativos de outras fontes para "pensar situações complexas, não-quantificáveis", especialmente para contextualizar 0 Estudo de caso (GODOY, 1995). Na pesquisa, buscamos dar conta do cotidiano qualitativamente através de entrevistas e grupos de discussão. A técnica 
de entrevista, segundo Gómez et al. (1996, p.168), "es uno de los medios para acceder al conocimiento, las creencias, los rituales, la vida de esa sociedad o cultura, obteniendo datos en el propio lenguaje de los sujetos". Como reconstruimos a intersecção entre publicidade, imaginário e consumo, essa técnica de coleta de dados individual é adequada porque permite aprofundar a discussão de temáticas particulares. Já os grupos de discussão são, para Méndez (2000, p.130), um "dispositivo de la reconstrucción del sentido social en el senso de una situación grupal discursiva". A pertinência do grupo de discussão remete ao fato de que através dele podemos "entender el comportamiento del sujeto en una sociedad de consumo en la que reina la grupalidad y la simbolización que forjan significaciones colectivas preconscientes a grupos de los sujetos/consumidores investigados" (MÉNDEZ, 2000, p.130).

0 universo dessa exploração é definido como um Estudo de caso que envolve dez mulheres adultas de índices socioeconômicos e idades diferentes, que trabalham na Universidade Católica de Pelotas e residem na cidade de Pelotas (Brasil), com quem estabelecemos contato entre os meses de setembro e outubro de 2007. Como $\operatorname{amostra}^{2}$, em segmentos de escolaridade e renda, temos um grupo de cinco informantes de índice socioeconômico referente à classe A-B, professoras da UCPel; e outro grupo de cinco informantes de índice socioeconômico referente à classe D-E, funcionárias da UCPel. Em termos de geração, nossas dez informantes formam cinco duplas de mesma faixa etária, porém mesclando índices socioeconômicos diferentes (uma mulher da Classe A-B e outra da Classe D-E em cada dupla de 20-30 anos, 30-40 anos, 40-50 anos, 50-59 anos, 60 anos).

Para explorar esse universo desde uma perspectiva pluri-metodológica, buscando compreender a publicidade na complexidade do cotidiano, trabalhamos do seguinte modo: I) aproximando-nos dos perfis, dos grupos, dos imaginários e das práticas de consumo dessas mulheres; II) para então estabelecer suas relações com os meios de comunicação, os usos que fazem da publicidade e suas competências de leitura desse gênero; III) e observar sua apropriação de um fluxo publicitário constituído a partir de seus hábitos de consumo dos meios e da publicidade (dados coletados em II), e também a visão dos grupos sobre as relações publicidade-imaginário-consumo. Esses três momentos remetem às Etapas da coleta e análise dos dados, planejadas para incluir a possibilidade

Na escolha dessa amostra, definimos o número de informantes a partir das exigências das técnicas de coleta de dados, especialmente grupos de discussão (que devem ter no mínimo cinco participantes que sejam pares) (MENDEZ, 2000), e das particularidades da abordagem qualitativa, segundo a qual a quantidade de fontes de dados é decidida ao longo da pesquisa, com 0 esgotamento da emergência de novas informações (GODOY, 1995; GÓMEZ et al., 1996). Já a eleição de quem seriam essas dez mulheres, se deu a partir de critérios qualitativos de seleção de amostra (GÓMEZ, 1996, p.135-148), para que permitissem explorar a diversidade de informações desejada, com a possibilidade de algumas semelhanças em relação aos níveis de escolaridade, de renda e à geração, chegando a uma primeira síntese por gênero de dez informantes do sexo feminino. 
de adequação de acordo com novas pistas que emergissem da observação.

Na Etapa I, a coleta e análise de dados foi individual, via entrevista, com foco nos temas do imaginário, cotidiano e consumo (tendo como instrumentos o "Roteiro de entrevista sobre Imaginário" e "Roteiro de entrevista sobre Práticas de consumo"). Na Etapa II, também individual, a coleta e análise de dados se deram via entrevista com as mesmas informantes, mas enfocando a publicidade (através de instrumentos que foram 0 "Roteiro de entrevista sobre Hábitos de consumo dos meios e da publicidade", o "Roteiro sobre Usos da publicidade" e o "Roteiro sobre Competências de leitura da publicidade"). Na Etapa III, coletiva e realizada através de dois grupos de discussão (cinco professoras em um e cinco funcionárias em outro), foram abordados conjuntamente os temas publicidade, imaginário e consumo (através do instrumento "Roteiro de grupos de discussão", elaborado no processo de pesquisa a partir dos resultados das Etapas I e II).

\section{Discussão teórica sobre o imaginário, o consumo e a publicidade}

Reunindo subsídios das áreas da Comunicação, das Ciências Sociais e da Filosofia buscamos uma abordagem teórica da publicidade, do imaginário e do consumo que respeite a complexidade de cada tema, oferecendo a possibilidade de compreender as suas intersecções.

Incialmente, debatemos a transversalidade do imaginário no cotidiano contemporâneo, partindo de uma reconstituição histórica da abordagem do imaginário que revela a diversidade de sentidos encontrados por seus estudiosos (imaginação, representação, ideologia, mitologia, simbólico) ${ }^{3}$. Chegamos então a uma abordagem do imaginário mais moderno e cotidiano em que se insere a publicidade, assim como "a paisagem urbana, os objetos familiares, os encontros fortuitos, os percursos ordinários, as distrações mais populares." (LEGROS et al., 2006, p.3).

Mas antes de explorar isso, retomamos as pistas de Durand (1997) sobre os processos de constituição do imaginário no cotidiano, que revelam o dinamismo e a reversibilidade das estruturas antropológicas do imaginário, abordadas a partir da bipartição entre dois "regimes" simbólicos, cuja alternância é explorada de forma análoga ao trajeto das águas: a "bacia semântica" da dinâmica do imaginário (DURAND,1998).

A partir daí, tomamos o cotidiano na sua pluralidade e criação como "perspectivação" para compreender o imaginário contemporâneo, seguindo os passos de Maffesoli (1988), cuja proposta engloba o micro e o macro na sua 
reversibilidade, diferentemente do cotidiano como objeto ou suporte para uma análise social crítica (TEDESC0, 1999). Antes disso, reconstituímos o campo de pesquisa do $\operatorname{cotidian} 0^{4}$, chegando à perspectiva compreensiva de considerar o todo, mesmo das grandes formas econômicas, políticas, sociais através da observação das pequenas coisas como "os gestos, a deambulação, o fato culinário, a errância sexual e a paixão amorosa, a indumentária, a cosmética, etc." (MAFFESOLI, 1988, p.69). Trata-se do cotidiano como lugar de um imaginário que é vetor de comunhão social.

\section{Restava então discutir o imaginário} contemporâneo e os indícios pós-modernos, a partir da saturação do moderno, retomando questões fundadoras desse debate ${ }^{5}$. Nos voltamos para as idéias de Maffesoli (2003a, p.12), para quem enquanto a modernidade é unificadora, a pós-modernidade é efervescente à exemplo de Dionísio, cuja sombra propaga a "importância do festivo, a potência da natureza e do entorno, o jogo das aparências, o retorno do cíclico acentuando o destino, coisas que fazem da existência uma sucessão de instantes eternos."
0 autor revela indícios da pós-modernidade no relativismo em diversos âmbitos sociais: 0 político descompromissado; o trabalho como mais um entre os diversos investimentos pessoais; a religião fragmentada em formas menores do sagrado; a família cedendo espaço ao sexo errante; o consumo hedonista; enfim, 0 social feito de uma multiplicidade de circuitos. (MAFFESOLI, 1988)

Nesse cenário, a vocação para a despesa, 0 consumo e o consumidor são discutidas a partir do pressuposto da despesa improdutiva como vocação humana, em contraponto complementar à produção e à nossa rendição moderna ao utilitarismo, de acordo com as idéias de Bataille (1975). A retomada da história da pesquisa sobre consumo, cultura e sociedade, revela a complexidade das abordagens emergentes a partir de mudanças históricas desde 0 século $\mathrm{XVI}^{6}$, chegando, segundo Barbosa (2004) ao debate contemporâneo sobre a sociedade ou cultura de consumo, e sobre a cultura material, revelando sua complexidade como:

Os processos sociais e subjetivos que estão na raiz da escolha de bens e serviços; quais são os valores, as práticas, os mecanismos de frui-

Tedesco (1999) aponta pressupostos do estudo do cotidiano tomados da sociologia geral e da perspectiva filosófica, presentes nas idéias de Durkheim, Simmel, Elias, Schutz, Husserl, Pareto e Weber; bem como na discussão de Parsons, Merton e seus colaboradores, e da Escola de Chicago; chegando ao interacionismo simbólico, a etnometodologia, o presentismo formista e a análise crítica do cotidiano.

Connor (1996) reconstitui a trajetória das idéias de Lyotard, junto a Jameson e Baudrillard.

Warnier (1999) indica esse caminho trilhado pela abordagem econômica ou pelas correntes da fenomenologia e do behaviorismo, do cognitivismo e da revalorização das respostas afetivas. Ele retoma o consumo sendo abordado no âmbito do consumo competitivo e ostentatório (Veblen, Elias, Bell, Baudrillard e Bourdieu), a moda e a distinção (Bell, Elias, Bourdieu), consumo como espaço de produção de sentido (Douglas), consumo como sistema de abastecimento (Fine e Leopold). 
ção e os processos de mediação social e que se presta o consumo; qual o impacto da cultura material na vida das pessoas e, ainda, como 0 consumo se conecta com outros aspectos da vida social, etc. (BARBOSA, 2004, p.29).

Abordamos então o consumidor e suas práticas desde a perspectiva de Certeau (1994), pelo viés da tática, que se opõe à modalidade estratégica do poder instituído. Esse consumidor, públicoalvo para a publicidade, é explorado na sua complexidade por diferentes áreas ${ }^{7}$ em termos dos níveis biológico, micro-individual, micro-social, meso-social e macro-social do processo de consumo, que remetem às variáveis internas e externas do comportamento do consumidor, debatido por Brée (2004). Para ele, além dos elementos que interferem no tratamento da informação à que tem acesso, o consumo e a decisão de compra são individualmente condicionados, entre outros aspectos, pelos desejos e motivações, atitudes, personalidade e estilo de vida. Socialmente, 0 consumo e a decisão de compra são condicionados, entre outros aspectos, pela identificação ou pertencimento a grupos com os quais a pessoa partilha a classe social, a idade, a religião, a etnia ou a raça. Tais aspectos podem ainda despertar 0 consumidor não pela sua afinidade natural, mas pela distinção ou projeção de aproximação de determinado grupo. (BRÉE, 2004)

Interseccionando essas discussões, a publicidade, como tecnologia do imaginário e do consumo, constitui junto ao marketing (de que é uma ferramenta) e à moda, um importante tripé para a compreensão do cotidiano pós-moderno, do consumo e do consumidor contemporâneo.

(CONNOR, 1996; SCHUDSON,1984; ROCHA, 2006)

Fruto de uma sintonia entre sedução e tecnologia, como podemos ver reunindo as idéias de Baudrillard (1991), Silva (2003) e Gomes (2003), a comunicação publicitária exige atenção às sutilezas desse jogo sedutor, dessa tentativa de comunhão simbólica permeada materialmente pelos objetos à venda. Longe de querer atribuir nome ao vencedor do jogo, interessa conhecer suas regras, a forma de jogar, os jogadores e o papel do imaginário e do consumo em suas jogadas.

Para isso, é preciso compreender o fundo ou contexto da publicidade, seu trajeto, processo e forma de fluxo, que configuram a presença da publicidade no cotidiano, como vimos antes (PIEDRAS, 2005). Assim, para dar conta dela, é preciso considerar a natureza multimidiática de sua forma, além da complexidade de seu fundo econômico-político-cultural atravessado pelo imaginário e o consumo. Se o continente da publicidade é multiforme, o conteúdo não pode fugir disso, e longe de definir características de suas imagens e textos, apenas revelamos a sua complexidade nos trajetos que carregam as subjetividades e objetividades cotidianas. 
Na concretude do cotidiano, além de compreender a natureza das práticas de publicitários e consumidores como fizemos (PIEDRAS, 2005), precisamos dar conta das intersecções entre quem faz e aqueles que consomem os anúncios do fluxo publicitário ${ }^{8}$, situando suas formas de ação (estratégicas e táticas) entre ofertas e apropriações. Nesse sentido, os hábitos de consumo dos meios de comunicação constituem o primeiro dispositivo para compreender isso, pois, como vimos, é através das mídias impressas, eletrônicas, digitais e alternativas, dos tempos e espaços dedicados a eles no cotidiano, que o consumidor é interpelado pelo fluxo publicitário.

Diante dos anúncios, a relação do consumidor com a publicidade é condicionada pelos usos que ele faz dessa forma de comunicação, apesar de sua função comercial. Como explica Jacks (2005, p.66), "os 'usos' são inalienáveis da situação sociocultural dos receptores que reelaboram, ressignificam e ressemantizam os conteúdos massivos, conforme sua experiência cultural, suporte de tais apropriações." Isso baliza dois momentos da articulação publicidade-imaginárioconsumo, a saber: 0 consumo simbólico dos anúncios, e o consumo material dos bens divulgados por eles, que são independentes, mas podem ser associados.

Outro fator que mobiliza as táticas do consumidor da publicidade são as suas competências de leitura deste gênero comunicativo. Segundo Gomes (2003, p.48), "os gêneros funcionam como uma espécie de manual de uso" das formas de comunicação. Através da experiência cotidiana de consumir um tipo de mensagem da mídia, 0 consumidor desenvolve sua compreensão das lógicas de troca de informação, linguagens e aparatos de comunicação. Na publicidade, cabe a ele reconhecer a forma como os anúncios são apresentados nos seus diversos meios, cortando fragmentos de programação e matérias informativas. É a partir desse reconhecimento das características formais, tecnológicas e discursivas da publicidade, que se constroem as possibilidades de negociação do sentido persuasivo de suas mensagens por parte das táticas dos consumidores.

Com essas pistas, ampliam-se as condições de compreender a articulação publicidadeimaginário-consumo desde a perspectiva do consumidor, explorando seus hábitos de consumo dos meios, usos da publicidade e competências de leitura, o que abordamos a seguir.

\section{Dados empíricos sobre cotidiano e imaginário, práticas de consumo, recepção da publicidade e apropriações do fluxo publicitário}

Entre o esforço teórico e o empírico, para

contextualizar o universo cotidiano das informantes de nosso Estudo de caso, reconstituímos através de dados secundários 
o cenário contemporâneo da cidade de Pelotas destacando sua vocação comercial, dados sobre consumo e comunicação, traçando alguns paralelos com a situação no estado e no país9. Logo, destacamos aspectos relativos à opção de trabalhar com feminino e não com o masculino, que remete a um consenso entre os estudiosos: as mulheres se ocupam do consumo com mais frequiência do que os homens (ENGEL; BLACKWELL; MINIARD, 2000) (JOHANSON; LEARNED, 2005). Nesse sentido, contamos com as idéias de Lipovetsky (2000), que aborda 0 imaginário feminino contemporâneo no âmbito do amor, do sexo, da beleza, do lar e do poder; o que é complementado pela discussão de Johanson e Learned (2005) sobre perfis e filtros de compra das consumidoras segundo suas gerações.

Ao longo da constituição de nossa amostra e do processo de coleta, descrição e análise dos dados, cuja definição metodológica já comentamos, chegamos a um rico conjunto de informações que sintetizamos nos quatro segmentos a seguir: cotidiano e imaginário feminino; práticas de consumo das mulheres; recepção da publicidade entre as informantes; e apropriações femininas do fluxo publicitário, sua relação com imaginário e consumo. Todos esses aspectos, que correspondem às diferentes etapas empíricas e campos teóricos da pesquisa, são apresentados em termos gerais, mas também com o devido destaque às diferenças associadas aos padrões de renda e escolaridade, e, menos intensamente, de idade.

Essas diferenças, consideradas na constituição do grupo de informantes, começam a ser reveladas no perfil das mulheres, em que percebemos a incidência da escolaridade, sintetizada no fato de que $8 \mathrm{~h}$ diárias de trabalho podem render de um a 15 salários mínimos, dependendo do nível de estudos. Esse desnível educacional e financeiro está diretamente ligado à moradia, pois todas as funcionárias (diferentes das professoras) residem no mesmo bairro periférico; e à etnia, já que as professoras têm origem européia e as funcionárias, africana.

\subsection{Cotidiano e imaginário}

Na tentativa de reconstituir o imaginário revelado pelo cotidiano das informantes, abordamos temas como trabalho, lazer, a diversidade de papéis vividos, aspectos da individualidade, as relações com as pessoas, com a natureza, com a religião, a política.

Todas as mulheres exercem uma atividade profissional em tempo integral, sendo a metade constituída por professoras universitárias e outra

Nesse exercício, contamos com as pesquisas do Instituto Técnico de Pesquisa e Assessoria (ITEPA/UCPel, 2003, 2006), do IBGE (Instituto Brasileiro de Geografia e Estatística), de uma pesquisa da agência de publicidade Oglivy Brasil (2005), e da Pesquisa Social Brasileira (2007), e com as reconstituições de Magalhães (1993), Silva (1996), Giacomini Filho (1991) e Toaldo (2005). Os dados sobre os meios de comunicação e veículos publicitários tem como fonte o Mídia Dados/IPOBE (Instituto Brasileiro de Opinião Pública e Estatística) (2004), além de planilhas de mídia distribuídas pelos veículos nas agências de publicidade da cidade de Pelotas. 
por funcionárias de serviços gerais da instituiçãa universitária. Quase todas as mulheres são mães. 0 lazer cotidiano nos finais de semana começa para a maioria delas com um turno de trabalho no sábado, e no tempo livre elas gostam de fazer coisas diferentes. Vantagens em termos de renda oferecem às professoras mais tempo livre, pois não cuidam a casa.

Simultaneamente, superando as diferenças de renda, escolaridade e idade, o grupo de convivência dessas mulheres é prioritariamente a família, mas elas concretamente partilham mais tempo com os colegas de trabalho. Outro aspecto comum é que encontros sociais e festas não fazem parte do dia-a-dia delas, mas as professoras, e não as funcionárias, semanalmente encontram familiares e amigos, em recepções em casa ou saída para restaurantes.

Os animais e as plantas sintetizam 0 imaginário relativo à natureza para elas, que também buscam essa ligação no ambiente externo. A beleza está no dia-a-dia de quase todas através das pessoas e suas atitudes, nos lugares e em si próprias. A saúde e o corpo são aspectos interligados para as mulheres, mas, além de uma perspectiva global, também revelam os condicionamentos da escolaridade e da renda (e não da idade).

A solidariedade está presente no cotidiano de todas as mulheres, independente do segmento e da idade. Já o posicionamento político está ausente no dia-a-dia da maioria delas. A religião institucionalizada não é praticada, apesar de a metade das informantes está ligada a uma crença (católica, evangélica cristã e espírita). 0 aqui-agora é valorizado pela maioria dessas mulheres e 0 prazer cotidiano está ligado, em grande parte, a conviver com pessoas queridas.

Para descrever sua personalidade, quase todas essas mulheres citam adjetivos ambivalentes e contraditórios. As pessoas com quem elas se identificam ou de que se distinguem, estão próximas (como familiares, colegas e amigos). A maioria delas se afirma "dona de si", responsável pelas suas decisões, mesmo considerando as opiniões alheias.

\subsection{Práticas de consumo}

Quanto às práticas de consumo, há diversidade nas condições de materiais de moradia e itens de posse, bem como atividades domésticas e de lazer, que variam fortemente entre o grupo de classe A-B (professoras) e C-D (funcionárias). Enquanto as funcionárias preferem fazer compra mensal, as professoras o fazem semanalmente. Nas compras, a maioria das mulheres prefere pagar com dinheiro à vista, mas quatro usam cartão de crédito, o que não indica diferença entre os segmentos ou a faixa etária. Elas afirmam que gastam seu dinheiro adequadamente, independente da renda ou escolaridade. Todas as professoras e apenas uma funcionária afirmam que investe seu dinheiro em coisas não materiais. 
0 que influencia 0 consumo para quase todas elas nos supermercados e lojas, são os preços e promoções; na mídia, a publicidade; na vida, a propaganda "boca-a-boca". No centro comercial, geralmente elas não compram, mas pagam contas e passeiam. Para elas, não é um problema voltar para a casa sem sacolas, exceto para duas mulheres de idade entre 20-30 anos.

Todas as informantes atribuem valor de uso a (quase) tudo o que compram. Sem precisar, só por comprar, como supérfluo, todas as funcionárias indicam cosméticos, e as professoras variedades. Os bens de consumo diante dos quais se sentem insaciáveis também mudam entre os segmentos.

\subsection{Recepção (individual) da publicidade - hábitos de consumo dos meios e da publicidade, usos da publicidade $\mathrm{e}$ competências de leitura dos anúncios}

Os hábitos de consumo dos meios dessas mulheres revelam que a mídia mais presente no seu cotidiano é a televisão, que todas assistem à noite preferencialmente na emissora Globo, assim como telefone celular que todas usam. As distinções referentes à escolaridade e à renda são explicitadas no segundo meio com que elas têm mais contato, o jornal para as professoras e o rádio para as funcionárias. A maioria das mulheres assiste a publicidade que "entra" na programação ou no seu dia-a-dia, o que ocorre através da televisão, dos encartes e das embalagens nos supermercado.
Os usos que essas mulheres fazem da publicidade são especialmente associados à informação sobre produtos e preços. No entanto, divergências relativas à escolaridade e à renda emergem através de palavras como orientação e instrução, citadas pelas funcionárias; meio de conhecer tendências e forma de entretenimento, entre as professoras.

Em termos gerais, os relatos dessas mulheres revelam que 0 lado bom da publicidade é indicar produtos e promoções, e um lado ruim remete à existência de anúncio demasiadamente intrusivos. Algumas afirmam que, quando vêem um anúncio publicitário, sentem alguma mudança, outras não. Na sua visão, há muita publicidade comercial (especialmente de bebidas) e pouca social e cultural. Os anúncios podem lhes atrair ou não em dois sentidos: 0 conteúdo, as marcas de produtos e serviços divulgados; ou a abordagem usada no anúncio, mais ou menos adequada. As marcas divulgadas pela publicidade são valorizadas pela maioria das mulheres, no entanto não são lembradas, 0 que é paradoxal.

Elas partilham competências de leitura que as tornam capazes de identificar os anúncios na programação midiática, diferenciando-os de outros gêneros da comunicação. Em termos gerais, essas mulheres reconhecem a função comercial da publicidade, mesmo quando esta é disfarçada, revelando desconfiança em relação a alguns anúncios. Em diferentes níveis, elas 
sabem quem e como se faz publicidade, sendo capazes de caracterizar suas imagens e textos, reproduzindo anúncios e apelos freqüentes.

Ao longo dessas observações gerais, há distinções baseadas nos níveis de escolaridade e renda que balizam essas experiências, a saber: 0 fato de que a visão das funcionárias está mais ligada a exemplos concretos e anúncios particulares, enquanto as professoras remetem a aspectos mais abstratos e generalistas da abordagem publicitária, independente do meio de comunicação. Essas disparidades tornam-se mais explícitas, por exemplo, na eleição dos anúncios que as fazem sonhar, "cair na real", de que gostam ou não; que as professoras elegem com base na identificação com aspectos abstratos presentes no contexto dos anúncios, enquanto as funcionárias enfatizam produtos concretos. As primeiras, talvez devido ao seu nível de escolaridade e acesso à informação, além de identificar e exemplificar vivências relativas à publicidade e seus anúncios, chegam a nomear alguns processos, às vezes através de uma linguagem institucionalizada no campo publicitário.

\subsection{Apropriações (coletivas) do fluxo publicitário x imaginário e consumo}

Partindo dessas percepções individuais sobre a publicidade, exploramos a relação publicidadeimaginário-consumo coletivamente, com a exposição de anúncios através de um fluxo publicitário televisivo capturado de um fragmento da programação noturna deste meio, no canal que a maioria das informantes afirmou assistir ${ }^{10}$.

Diante do fluxo publicitário ofertado pela produção, composto por 14 anúncios de 15 e 30 segundos, que expusemos aos dois grupos (um das informantes professoras e outro das funcionárias), todas as mulheres comentaram gostar de três: as marcas Bradesco e Big, e Biorene, revelando uma apropriação tática das ofertas do fluxo da produção (o fluxo publicitário da recepção), que inclui intenso descarte de anúncios considerados irrelevantes. Apesar de gostar desses três anúncios, nenhuma das mulheres é consumidora dos serviços do banco Bradesco e dos cosméticos Biorene, e apenas duas ocasionalmente compram no hipermercado Big.

As diferentes motivações para a apreciação dos anúncios demonstram a implicância da pessoa e seu contexto na produção de sentidos sobre a publicidade, tornando evidente a sua intertextualidade e reiterando distinções baseadas nos níveis de escolaridade e renda que balizam duas lógicas de recepção: mais concreta entre as funcionárias, focadas no produto, interessadas pela informação; e mais abstrata entre as professoras que enfatizam a situação, atraídas pela estética.

Em termos gerais, o consumo dos próprios anúncios (três), ainda que seletivo em relação ao 
todo (14), é superior ao consumo dos produtos anunciados (um), e o potencial de intersecção entre os dois tipos de consumo (simbólico e material) é concreto para uma minoria das informantes. Segundo esses relatos, sonhar com a publicidade independe fato de adquirir os produtos anunciados, indicando a proeminência da dimensão estética e a defasagem entre a dimensão funcional da publicidade e a compra do produto, que pode vir bem depois. Entretanto, além de outros fatores de influência (lojas, mídia em geral e propaganda "boca-a-boca"), a publicidade condiciona as práticas de consumo dessas mulheres pela indicação dos preços baixos e promoções, fornecendo um mapa de localizações, nomes e características de produtos. Além disso, as situações em que consomem influenciadas pelos anúncios publicitários sem perceber são inúmeras, apesar das competências para identificar essas mensagens e negociar seus sentidos.

\section{Considerações finais}

Escapando às conclusões, conscientes da impossibilidade de sintetizar a riqueza do que tivemos a oportunidade de compreender, restanos a humildade de reconhecer a complexidade dos fatos, e também dos dados; inclusive pelos limites deste artigo, que nos impedem de retomar questões teóricas. Diante das abordagens deterministas e do imenso poder atribuído por elas à publicidade, cremos que nosso êxito é reunir argumentos para uma postura que a aceite e compreenda, ao invés de julgá-la.
Apresentamos então alguns indícios que, longe de propor qualquer generalização, remetem a fatos concretos e localizados. Pois nos contentamos em saber que para essas dez mulheres de Pelotas que brindaram a pesquisa com suas vivências, o imaginário pós-moderno é transversal, num cotidiano marcado pelo relativismo, o holismo, a comunhão, o prazer, a estética... apesar das rotinas, escolaridades, rendas e idades. Suas práticas de consumo são naturalizadas e ligadas à uma mescla de ornamentos simbólicos e fundamentos materiais, articulados com habilidade no cotidiano, para adquirir, usar e descartar o que for (des)necessário ou (in) útil. Na sua relação audiovisual com os meios de comunicação, a publicidade as interpela, assim como nos tempos e espaços de leitura, trajeto, lazer, trabalho. Elas recebem-nas, ou não; usufruem-nas, ou não; compreendem-nas, ou não; criticam-nas, ou não.

Mas as relações dessas mulheres com a publicidade, o consumo e o imaginário são fortemente atravessadas pelos diferentes níveis de escolaridade e de renda, e, em menor escala nesta observação, variações de idade. A incidência desses condicionamentos individuais e sociais foi revelada de forma global no cotidiano das informantes dessa pesquisa, interpelando seu trabalho, seu lazer, sua relação com a natureza, a beleza, a política, a religião, as outras pessoas, as decisões de consumo, o consumo dos meios de comunicação, a exposição à publicidade e, além de tudo isso, a relação com os anúncios, 
usos e competências de negociação de sentidos.

Se 0 imaginário incide nas dinâmicas cotidianas através de trajetos entre sub/objetividades, a impressão que tivemos é de que as intimações objetivas implicam mais fortemente 0 cotidiano daquelas menos escolarizadas e conseqüentemente de menor renda, enquanto as outras mulheres podem exercitar mais livremente suas pulsões subjetivas.

Apesar dessas reconhecidas variações de escolaridade, renda e idade, reunimos indícios de que na relação destas mulheres com a publicidade e 0 consumo - atravessada pelo imaginário -, proliferam-se uma diversidade de táticas. Diante dos anúncios, no fluxo ofertado pelas agências e anunciantes, onipresentes no cotidiano, as receptoras configuram o seu fluxo particular, mobilizados pela complexidade das demandas dos seus tempos, espaços e desejos.

Enfim, diante da complexa tríade publicidadeimaginário-consumo, cabe primeiro conceder a cada um o seu lugar, para depois lembrar que a publicidade é simbolicamente atravessada pelo imaginário e pelo consumo, às vezes concretamente associada a este, que também pode realizar-se independente dela. Num cotidiano em que adquirir a "real beleza de Dove" pode custar para uns 12min, para outros 3h de "trabalho real", apenas "sonhar não custa nada". Se a implicação mútua entre publicidade e imaginário é perpétua, o mesmo não se pode dizer da relação publicidade-consumo, já que a incidência da publicidade é incomensurável, o que não nos exime de desconfiar de sua eficiência.

\section{Referências bibliográficas}

BARBOSA, Lívia. Sociedade de consumo. Rio de Janeiro: Zahar, 2004.

BATAILLE, Georges. A parte maldita. Rio de Janeiro: Imago, 1975.

BAUDRILLARD, Jean. Da sedução. Campinas: Papirus, 1991.

BRÉE, Joël. Le comportement du consommateur. Paris: Dunod, 2004

CERTEAU, Michel. A invenção do cotidiano: 1.artes de fazer. Petrópolis: Vozes, 1994.

CONNOR, Steven. Cultura e pós-modernidade: introdução às teorias do contemporâneo. São Paulo: Loyola, 1996.

DURAND, Gilbert. As estruturas antropológicas do imaginário: introdução à arqueologia geral. São Paulo: Martins Fontes, 1997.

0 Imaginário: ensaio acerca das ciências e da filosofia da imagem. Rio de Janeiro: DIFEL, 1998.

ENGEL, James; BLACKWELL, Roger; MINIARD, Paul. Comportamento do consumidor. Rio de Janeiro: Livros Técnicos e Científicos Editora, 2000.

\section{GIACOMINI FILHO, Gino. Consumidor Versus}

Propaganda. São Paulo: Summus, 1991.

GOD0Y, Arlinda S. Pesquisa qualitativa: tipos fundamentais. RAE- Revista de Administração de Empresas, São Paulo, v. 35, n. 3 - maio/ jun. 1995. GOLDENBERG, Mirian. A arte de pesquisar: como fazer pesquisa qualitativa em ciências sociais. Rio de Janeiro: Record, 2003.

GOMES, Neusa. Publicidade: comunicação persuasiva. Porto Alegre: Sulina, 2003. 
GOMES, Itania. Efeito e recepção: a interpretação do processo receptivo em duas tradições de investigação sobre os media. In: GOMES, I.; JACOB, C. Media e cultura. Salvador: Pós-Graduação em Comunicação e Cultura Contemporâneas, 2003.

GÓMEZ, Gregorio; FLORES, Javier; e JIMÉNEZ, Eduardo. Metodología de la investigación cualitativa. Málaga: Aljibe, 1996.

IBGE. Instituto Brasileiro de Geografia e Estatística. Disponível em: <www.ibge.gov.br>. Acesso em: 10 dez. 2005.

IB0PE. Instituto Brasileiro de Opinião Pública e Estatística. Disponível em: <www.ibope.com.br>. Acesso em: 07 set. 2004.

IPCA/IBGE. Disponível em: <http://www.ai.com.br/ pessoal/indices/CLASSES.HTM>. Acesso em: ago.2007.

ITEPA, Índice Potencial de Consumo e segmentação deste nas famílias do município de Pelotas conforme os critérios: Grupos de Produtos, Produtos, Classes Sociais e Áreas de Residência. 2003.

.Universidade Católica de Pelotas. Instituto

Técnico de Pesquisa e Assessoria. Banco de Dados da Zona Sul - RS - ITEPA - Pelotas: EDUCAT, 2006a.

INFORME SÓCIOECONÔMICO Nº. 19, DISTRIBUIÇÃO DA MÃO-DE-OBRA OCUPADA POR ATIVIDADE ECONÔMICA NO MUNICÍPIO DE PELOTAS E NOS DEMAIS MUNICÍPIOS DO EIXO ECONÔMICO PELOTAS / RIO GRANDE. Banco de Dados da Zona Sul - RS - ITEPA - Pelotas: 2006b Disponível em: <http://www.ucpel.tche.br/ itepa/>. Acesso em: ago.2007.

JACKS, Nilda; ESCOSTEGUY, Ana Carolina. Comunicação e recepção. São Paulo: Ed. Hacker, 2005. JOHANSON, Lisa; LEARNED, Andrea. Por que as mulheres compram? Estratégias de marketing para conquistar um novo público. São Paulo: Futura, 2005.
KOTLER, Philip. Princípios de marketing. Rio de Janeiro: LTC, 1998.

LEGROS, Patrick; MONNEYRON, Fréderic; RENARD, Jean-Bruno; TACUSSEL, Patrick. Sociologie de

l'imaginaire. Paris: Arman Colin, 2006.

LIPOVETSKY, Gilles. A terceira mulher: permanência e revolução do feminino. São Paulo: Companhia das Letras, 2000.

MAFFESOLI, Michel. 0 conhecimento comum: compêndio de sociologia compreensiva. São Paulo: Brasiliense, 1988.

0 instante eterno: 0 retorno do trágico nas sociedades pós-modernas. São Paulo: Zouk, 2003a. A comunicação sem fim (teoria pós-moderna da comunicação). In: Revista FAMECOS, Porto Alegre, n. 20, abril 2003b.

A comunicação sem fim. In: MARTINS, F.; SILVA, J. (orgs). A genealogia do virtual: comunicação, cultura e tecnologias do imaginário. Porto Alegre: Sulina, 2004a.

MAGALHÃES, Mario. 0pulência e cultura na província de São Pedro do Rio Grande do Sul. Pelotas: EdUFPel / Livraria Mundial, 1993.

MARTÍN-BARBERO, Jesús. Dos meios às mediações: comunicação, cultura e hegemonia. Rio de Janeiro: UFRJ, 2003.

MÉNDEZ, Maria Guadalupe. Apuntes metodológicos sobre el papel de la técnica del grupo de discusión en la construcción de conocimiento científico: algunas reflexiones sobre una aplicación concreta en la investigación social. Estudios de las culturas contemporáneas. Época II, v. 6, n.12, dez. 2000.

PIEDRAS, Elisa. A articulação da publicidade com o mundo social: a constituição do fluxo publicitário nas práticas de produção e de recepção. 2005. Dissertação (Mestrado em Comunicação e 
Informação)- Universidade Federal do Rio Grande do Sul, Porto Alegre, 2005

Publicidade, imaginário e consumo:

anúncios no cotidiano feminino. 2007. Tese (Doutorado

em Comunicação Social)- Pontfícia Universidade

Católica do Rio Grande do Sul, Porto Alegre, 2007.

ROCHA, Everardo. Representações do consumo:

estudos sobre a narrativa publicitária. Rio de Janeiro:

PUC-Rio; Mauad, 2006.

SCHUDSON, Michael. Advertising, the uneasy

persuasion: its dubious impact on American society.

New York: BasicBooks, 1984.

SILVA, Juremir. Anjos da perdição: futuro e presente na cultura brasileira. Porto Alegre: Sulina, 1996.

As tecnologias do imaginário. Porto Alegre:

Sulina, 2003.

SISSORS, Jack. Planejamento de mídia. São Paulo:

Nobel, 2001.

SOLOMON, Michael. 0 comportamento do

consumidor: comprando, possuindo e sendo. Porto

Alegre: Bookman,2002.

TEDESCO, João. Paradigmas do cotidiano:

introdução à constituição de um campo de análise

social. Santa cruz do Sul: EDUNISC, 1999.

TOALDO, Mariângela. Cenário publicitário

brasileiro: anúncios e moralidade contemporânea.

Porto Alegre: Sulina, 2005.

WARNIER, Jean-Pierre. Construire la culture

matérielle. Paris: PUF, 1999.

WILLIAMS, Raymond. Télévision: Technology and

Cultural Form. London: Wesleyan University Press, 1992b. 
Publicity, imaginary and consumption: ads in feminine everyday life

\section{Abstract}

In this research, we start from the following problem: How do imaginary and consumption cross people's everyday life relation to advertising? How do they define their relation to advertising, which use do they make of it, which competence do they develop to comprehend it, how do they appropriate advertising flow? Therefore, we explored how imaginary crosses advertising, its relations with consumption in a post-modern configuration; and persuasive communication as an imaginary seduction, its everyday life background, form and practice. Through the methodological strategy that mixes interviews and focal groups, we analyze how adult women report on their imaginary, their consumption practice, and especially their relation to advertising; obtaining results that set out conditions related to income and schooling.

\section{Keywords}

Advertising. Imaginary. Consumption.

Everyday life. Woman.

\section{Publicidad, imaginario y consumo: anuncios en el cotidiano femenino}

\section{Resumen}

En esta investigación empezamos desde el siguiente problema: ¿Cómo el imaginario y el consumo atraviesan la relación cotidiana de las personas a través de la publicidad? ¿Cómo ellas definen su relación con la publicidad, cuáles los usos que hacen de ella, qué capacidades han desarrollado para comprenderla, cómo se apropian del flujo publicitario? Posteriormente, exploramos como el imaginario cruza la publicidad, su relación con el consumo en su configuración posmoderna; y la comunicación vehemente como tecnología del imaginario y de la seducción, su fondo, formas y prácticas del cotidiano. A través de una estrategia metodológica que mezcla entrevistas y grupos de discusión, observamos las narraciones de mujeres adultas sobre su imaginario, sus prácticas de consumo y en especial su relación con la publicidad; llegando a resultados que explicitan condicionantes relacionados a la renta y al nivel de escolaridad.

\section{Palabras clave}

Publicidad. Imaginario. Consumo.

Cotidiano. Mujer. 


\section{Expediente}

A revista E-Compós é a publicação científica em formato eletrônico da Associação Nacional dos Programas de Pós-Graduação em Comunicação (Compós). Lançada em 2004, tem como principal finalidade difundir a produção acadêmica de pesquisadores da área de Comunicação, inseridos em instituições do Brasil e do exterior.
E-COMPÓS I www.e-compos.org.br I E-ISSN 1808-2599

Revista da Associação Nacional dos Programas de Pós-Graduação em Comunicação. Brasília, v.11, n.3, set./dez. 2008

A identificação das edições, a partir de 2008 passa a ser volume anual com três números.

\section{CONSELHO EDITORIAL}

\section{Afonso Albuquerque}

Universidade Federal Fluminense, Brasil

Alberto Carlos Augusto Klein

Universidade Estadual de Londrina, Brasi

Alex Fernando Teixeira Primo

Universidade Federal do Rio Grande do Sul, Brasil

\section{Alfredo Vizeu}

Universidade Federal de Pernambuco, Brasil

Ana Carolina Damboriarena Escosteguy

Pontifícia Universidade Católica do Rio Grande do Sul, Bras

Ana Silvia Lopes Davi Médola

Universidade Estadual Paulista, Brasil

André Luiz Martins Lemos

Universidade Federal da Bahia, Brasil

Ângela Freire Prysthon

Universidade Federal de Pernambuco, Brasil

Antônio Fausto Neto

Universidade do Vale do Rio dos Sinos, Brasil

Antonio Carlos Hohlfeldt

Pontifícia Universidade Católica do Rio Grande do Sul, Brasil

Arlindo Ribeiro Machado

Universidade de São Paulo, Brasil

César Geraldo Guimarães

Universidade Federal de Minas Gerais, Brasil

Cristiane Freitas Gutfreind

Pontifícia Universidade Católica do Rio Grande do Sul, Brasil

Denilson Lopes

Universidade Federal do Rio de Janeiro, Brasil

Eduardo Peñuela Cañizal

Universidade Paulista, Brasi

Erick Felinto de Oliveira

Universidade do Estado do Rio de Janeiro, Brasil

Francisco Menezes Martins

Universidade Tuiuti do Paraná, Brasil

Gelson Santana

Universidade Anhembi/Morumbi, Brasi

Hector Ospina

Universidad de Manizales, Colômbia

leda Tucherman

Universidade Federal do Rio de Janeiro, Brasil

Itania Maria Mota Gomes

Universidade Federal da Bahia, Brasil

Janice Caiafa

Universidade Federal do Rio de Janeiro, Brasil

Jeder Silveira Janotti Junior

Universidade Federal da Bahia, Brasil

\section{João Freire Filho}

Universidade Federal do Rio de Janeiro, Brasil

John DH Downing

University of Texas at Austin, Estados Unidos

José Luiz Aidar Prado

Pontifícia Universidade Católica de São Paulo, Brasil

José Luiz Warren Jardim Gomes Braga

Universidade do Vale do Rio dos Sinos, Brasil

Juremir Machado da Silva

Pontifícia Universidade Católica do Rio Grande do Sul, Brasil

Lorraine Leu

University of Bristol, Grã-Bretanha

Luiz Claudio Martino

Universidade de Brasília, Brasil

Maria Immacolata Vassallo de Lopes

Universidade de São Paulo, Brasil

Maria Lucia Santaella

Pontifícia Universidade Católica de São Paulo, Brasil

Mauro Pereira Porto

Tulane University, Estados Unidos

Muniz Sodre de Araujo Cabral

Universidade Federal do Rio de Janeiro, Brasil

Nilda Aparecida Jacks

Universidade Federal do Rio Grande do Sul, Brasil

Paulo Roberto Gibaldi Vaz

Universidade Federal do Rio de Janeiro, Brasil

Renato Cordeiro Gomes

Pontifícia Universidade Católica do Rio de Janeiro, Brasil

Ronaldo George Hela

Universidade do Estado do Rio de Janeiro, Brasil

Rosana de Lima Soares

Universidade de São Paulo, Brasil

Rossana Reguillo

Instituto Tecnológico y de Estudios Superiores do Occidente, México

Rousiley Celi Moreira Maia

Universidade Federal de Minas Gerais, Brasil

Sebastião Carlos de Morais Squirra

Universidade Metodista de São Paulo, Brasi

Simone Maria Andrade Pereira de Sá

Universidade Federal Fluminense, Brasil

Suzete Venturelli

Universidade de Brasília, Brasil

Valério Cruz Brittos

Universidade do Vale do Rio dos Sinos, Brasil

Veneza Mayora Ronsini

Universidade Federal de Santa Maria, Brasil

Vera Regina Veiga França

Universidade Federal de Minas Gerais, Brasil
COMISSÃO EDITORIAL

Ana Gruszynski I Universidade Federal do Rio Grande do Sul, Brasil

Rose Melo Rocha I Escola Superior de Propaganda e Marketing, Brasil

\section{CONSULTORES AD HOC}

Alexsandro Galeno Araújo Dantas I Universidade Federal do Rio Grande do Norte, Brasil Isaltina Gomes I Universidade Federal de Pernambuco, Bras João Luís Anzanello Carrascoza I Escola Superior de Propaganda e Marketing, Brasil Malena Segura Contrera I Universidade Paulista, Brasil

Marcia Benetti I Universidade Federal do Rio Grande do Sul, Brasi

Maria Aparecida Baccega I Universidade de São Paulo, Bras

Vander Casaqui I Escola Superior de Propaganda e Marketing, Brasil

Virginia Pradelina da Silveira Fonseca I Universidade Federal do Rio Grande do Sul, Brasil

REVISÃO DE TEXTO E TRADUÇÃo I Everton Cardoso

ASSISTÊNCIA EDITORIAL E EDITORAÇÃO ELETRÔNICA I Raquel Castedo
COMPós I www.compos.org.br

Associação Nacional dos Programas de Pós-Graduação em Comunicação

Presidente

Erick Felinto de Oliveira

Universidade do Estado do Rio de Janeiro, Brasil erickfelinto@uol.com.br

Vice-presidente

Ana Silvia Lopes Davi Médola

Universidade Estadual Paulista, Brasil

asilvia@faac.unesp.br

Secretária-Geral

Denize Correa Araújo

Universidade Tuiuti do Paraná, Brasil

denizearaujo@hotmail.com 